\title{
Impact of humanities and social sciences curriculum in an undergraduate medical education programme
}

\author{
Kulsoom Ghias \\ Aga Khan University, kulsoom.ghias@aku.edu \\ Kausar S. Khan \\ Aga Khan University, kausar.skhan@aku.edu \\ Rukhsana Ali \\ Aga Khan University, rukhsana.ali@aku.edu \\ Shireen Azfar \\ Aga Khan University, shireen.azfar@aku.edu \\ Rashida Ahmed \\ Aga Khan University, rashida.ahmed@aku.edu
}

Follow this and additional works at: https://ecommons.aku.edu/pakistan_fhs_mc_bbs

Part of the Curriculum and Instruction Commons, Life Sciences Commons, and the Medical Education Commons

\section{Recommended Citation}

Ghias, K., Khan, K. S., Ali, R., Azfar, S., Ahmed, R. (2020). Impact of humanities and social sciences curriculum in an undergraduate medical education programme. JPMA. The Journal of the Pakistan Medical Association, 70(9), 1516-1522.

Available at: https://ecommons.aku.edu/pakistan_fhs_mc_bbs/873 


\title{
Impact of humanities and social sciences curriculum in an undergraduate medical education programme
}

\author{
Kulsoom Ghias¹, Kausar Saeed Khan², Rukhsana Ali3 , Shireen Azfar4, Rashida Ahmed5
}

\begin{abstract}
Objective: To evaluate the impact of humanities and social sciences curriculum in an undergraduate medical education programme.

Methods: The qualitative study was conducted from May 2016 to May 2017 at a private medical college in Karachi where humanities and social sciences subject is an art of the undergraduate curriculum as a 6-week module at the start of Year 1 of the five-year programme. Focus group discussions were held with students from all the five years as well as with faculty related to humanities and social sciences, basic sciences and their clinical counterparts. The views of alumni of the undergraduate programme who are now members of the faculty at the institution were also explored and semi-structured interviews were conducted with institutional academic leaders. MAXQDA software was used to identify the themes for analysis. Results: Of the 50 participants, 27(54\%) were students, 21(42\%) were faculty members and 2(4\%) were academic leaders. From the 11 sub-themes, 5 themes were identified: Expectations, Strengths, Challenges, Way forward, and Institutional role and responsibility. Faculty members perceived humanities and social sciences as encouraging creative and critical thinking, boosting students' confidence and positively impacting their behaviour. Student perception seemed to change as they progressed through the years and they appreciated its impact at different stages.

Conclusion: The existing humanities and social sciences curriculum can be further strengthened by integrating contents throughout the five-year programme and continuing it as a longitudinal theme rather than limiting it to a one-time exposure at the start of the programme.
\end{abstract}

Keywords: Education, Medical, Undergraduate, Humanities, Curriculum.

(JPMA 70: 1516; 2020) DOI: https://doi.org/10.5455/JPMA.24043

\section{Introduction}

It has been argued that while science is important for the development of technical judgement, arts and humanities are crucial for the development of humane judgement. The two together form the clinical judgement required to be a "good" doctor. ${ }^{1}$ As per the Aristotelian concept, humanities are integral to physicians' personhood, bridging identity and activity. 2,3 Medical schools, particularly in the Western world, have incorporated humanities, social sciences and arts into their curricula 4,5 on the premise that these disciplines promote understanding of the world and foster compassion and empathy. 6 However, evidence of this effort in developing countries is scarce.

In Pakistan, students enter medical college at 18 years upon completion of higher secondary education, with a focus on required science subjects, to pursue a "respectable" and "lucrative" profession. The Pakistan Medical and Dental Council (PMDC) does not require that students entering medical colleges should have a broad-based education or

${ }^{1}$ Department of Biomedical and Biological Sciences, Aga Khan University, 2Department of Community Health Sciences, Aga Khan University, ${ }^{3}$ Undergraduate Medical Education Curriculum Unit, Aga Khan University, Karachi, Pakistan; ${ }^{4}$ Aga Khan University; ${ }^{5}$ Department of Pathology \& Laboratory Medicine, Aga Khan University, Karachi, Pakistan

Correspondence: Kulsoom Ghias e-mail: kulsoom.ghias@aku.edu that the medical curriculum should provide it. It only requires inclusion of Islamiat and Pakistan Studies, but does not define curricular content. The challenge for medical colleges lies in developing graduates who can ultimately appreciate their role and responsibilities as physicians in the communities they serve and be willing agents within an inherently weak, poorly-regulated and often unethical healthcare system that marginalises non-affording patients.

To address this, a private medical college in Karachi adopted a novel and indigenously developed approach to include humanities, arts and social science (HASS) courses in its five-year undergraduate medical curriculum to meet clearly-defined competencies. Specifically, the intended purpose of HASS is to develop graduates who are sensitive and reflective members of society, and who respect diversity/differences. Furthermore, students should understand and uphold the values of honesty, integrity, generosity, kindness and empathy, particularly in their professional life. HASS has been conceptualised and implemented as a 6-week concentrated module at the start of Year 1 of the five-year undergraduate medical programme since 2012. In addition to three mandatory courses (Islamiat and Pakistan Studies, with a focus on pluralism and respect in both courses, and Urdu Communication), students are required to select three 


\section{courses from a 15-20 options of HASS elective offerings. ${ }^{7}$}

The current study was planned to present a qualitative evaluation of the HASS programme.

\section{Subjects and Methods}

The qualitative study with a participatory approach was conducted from May 2016 to May 2017 at a medical college in Karachi. Following approval by the institutional ethics review committee, students across all five years and faculty were invited to participate in focus group discussions (FGDs). In-depth interviews were also used for datagathering. Secondary data sources included student evaluations and student products of HASS courses.

Two strategies were employed for the selection of study participants. Volunteer sampling was used in the case of students and faculty for FGDs. Key informants were identified through purposive sampling for semi-structured interviews with the academic leaders. Students enrolled were from all the academic years, specifically from the

Appendix: Questions for student and faculty FGDS and interview guide for AKU leadership

\section{Students}

1. What were your expectations of HASS before you started the programme?

2. Are you aware of the goals and objectives of the HASS programme? Do you feel these objectives were met?

3. Did your perception of the HASS programme change as you progressed through medical college?

4. What were the strengths and limitations of the HASS programme?

5. How can HASS be improved? What changes would you recommend? What should remain unchanged?

6. Should HASS be taught longitudinally beyond Year 1? Why? Why not? If yes, what are your recommendations/suggestions for this change?

7. What impact, if any, do you think HASS has had on you as a person and as a future health professional?

Faculty

1. What is your perception of HASS?

2. What is the contribution of HASS to the medical curriculum and development of a health professional? Does HASS contribute in any way to the development of required competencies?

3. What impact, if any, do you think HASS has on students and their behaviour?

4. What changes would you recommend to improve the HASS programme?

5. Would you recommend that HASS be taught beyond the first year of medical school?

6. [If medical college faculty] Would you have wanted humanities and social sciences as part of your curriculum? Why? Why not?

7. Anything else you would like to say about HASS in the UGME in light of your exposure to current students at AKU?

Academic leaders

1. What is the institutional vision for incorporation of HASS in medical curriculum?

2. What do you think is the importance/relevance of teaching HASS in UGME?

3. What is your position on making HASS a longitudinal theme for the UGME?

NOTES: One author's name has an initial in it. batches of 2016-2020. Faculty members included HASS faculty, other medical college faculty and those who were alumni of the undergraduate medical education (UGME) programme from pre-HASS years. A total of nine FGDs with 5-10 participants were conducted. In-depth interviews with identified key informants were conducted in a semistructured format with Dean of the Medical College and the Founding Dean of the Faculty of Arts and Sciences.

Open-ended questions were posed in the FGDs and interviews (Appendix). The interviews and FGDs were transcribed and sent to the participants for memberchecking. MAXQDA software was used to identify the themes for analysis.

\section{Results}

Of the 50 participants, 27(54\%) were students, 21(42\%) were faculty members and $2(4 \%)$ were academic leaders. A total 11 sub-themes emerged from the multi-voice narratives with students, faculty and leadership. These were: hopes and fears; why is HASS important; what did HASS do for me (students voice); what did HASS do for/to students (faculty voice); what worked in HASS; what didn't work in HASS; what should happen to HASS; HASS as a longitudinal theme; how to make HASS a longitudinal theme; challenges for HASS and how to address them; what can/should the institution do to support HASS. These sub-themes were collated into five themes: Expectations, Strengths, Challenges, Way forward, and Institutional role and responsibility (Figure 1).

Qualitative results were expressed as a multi-voice narrative to allows the reader to 'hear' all the three voices directly without third-part mediation.

First, the voice of the students: I was told [by seniors], "You are going to have fun, but it will be a waste of time." At the end, I realized it was not [what] we [had] hoped (Year 1). I didn't have any expectations from HASS, but it was a good time to adapt into the system (Year 1). I was more excited about HASS than medicine; never imagined we will be doing different things (Year 4). When I found out about HASS ... I [thought] this is so cool. Over here you go to med school, engineering school and business school. It is so one-tracked ... I was super excited (Year 5). Initially, I thought it would be useful, but ... (Year 1). One of the objectives of HASS was that it would help us broaden our horizons. It didn't happen at all (Year 1). [HASS] opened up new horizons (Year 3) ... sensitized me, broadened my mind (Year 4). We think medicine is the toughest, but there is this tough world outside [and] start to think about other people's lives ... you can't belittle anyone ... it's [about] respecting others (Year 4). In clinical years, we realised there are different points of view (Year 4). The religion course 


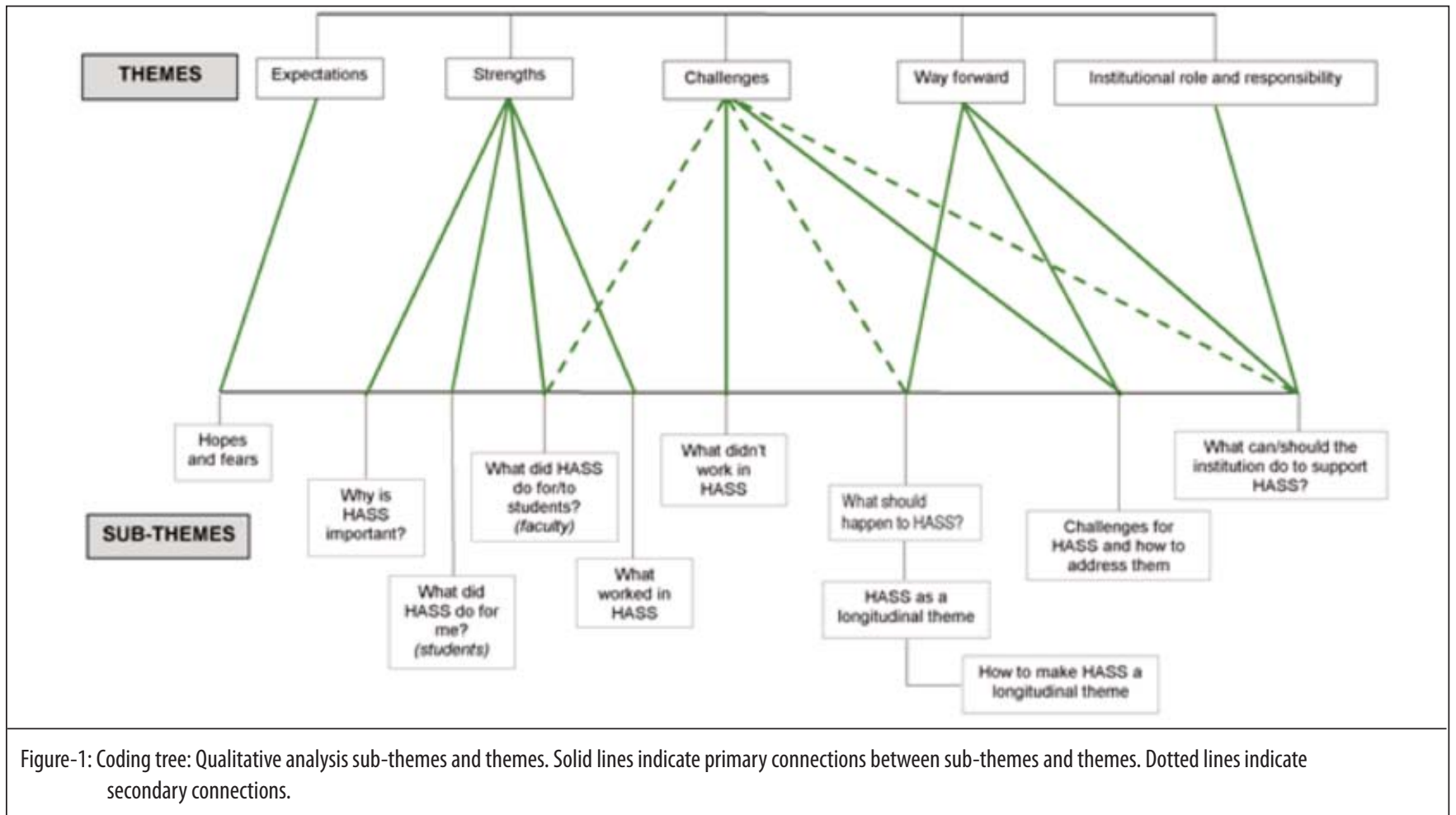

affected me specifically. I now have an understanding of the faith the patient belongs to, I am informed. I [noticed this] change in me after HASS. I really appreciated it (Year 3). I became more religiously tolerant. I started respecting [others] more (Year 5). [HASS] made me a better medical student ... I always remember HASS when dealing with patients ... not be detached, cannot ignore the patients ... need to talk to them, look them in the eye and be very empathetic ... (Year 3). I thought I am doing art and English literature, fun, woohoo, but these became significant afterwards in clinics and rounds (Year 5). The strength [of HASS] was the diversity of subjects offered (Year 3). HASS was an ice-breaker; it brought all of [us] together (Year 2) ... eased us into medicine, we were not overburdened from the first day with medicine (Year 2). After a few weeks, I wanted to do something else which was more medicinerelated (Year 4) ... the faculty is divided; non-HASS faculty probably think "What are you doing? Why are you wasting time?" (Year 5). To have HASS as a longitudinal theme is a very good idea ... at the end of five years I don't want medical education to be the only thing I do (Year 2). If it is not a continuous process, it's not going to bring as much change (Year 3). Having classes for the next four or five years would be a de-stressor (Year 4). I would like a break from thinking about medicine all the time. It's a lot of sadness that we have to deal with and we have to grow up a lot in a really short amount of time (Year 5 ). HASS should be separated from medicine rather than being a part of medicine (Year 4) ... have interesting talks on various subjects that would broaden horizons; there doesn't have to be a test (Year 1).

The other voice was that of the faculty: HASS has the potential to make them good human beings (Alumnus faculty). To understand human suffering, a respect for the canvas is important, that perspective is provided by HASS. The perspective we bring to the bedside makes all the difference (Alumnus faculty). By becoming empathetic and compassionate, they are likely to keep their clinical career patient-centric (Alumnus faculty). Medicine isn't about just the science; studying humanities helps develop interest and skills to unwind from a stressful schedule (Alumnus faculty). HASS brings out-of-the-box, creative thinking (Faculty) ... plays a role in thinking about the world outside (Faculty) gives insight otherwise not given in the curriculum (Alumnus faculty) ... provides an opportunity to gel together and tolerance develops (HASS faculty). There is a greater degree of openness amongst them (HASS faculty).

Students form groups coming from the same schools, from the same cities, yet there are students who are still on the fringes, they are not able to gel with the rest (Faculty). I don't see any difference in the students (Faculty) ... don't know long-term effect [of HASS] (Faculty). This is our trademark - we are proud of it (Faculty). HASS needs to be incorporated in daily medical practice (Faculty) ... create a 
different narrative (Alumnus faculty) ... a physician who plays music can come in and say "this is what music does for me, how it helps me be a successful physician", someone who writes can say, "I am writing and it helps me be a better physician" (HASS faculty). I think HASS should be a longitudinal theme weaved into the five-year medical curriculum (Faculty). Compassion and empathy erode. To maintain the students' humane attitude, their compassion, HASS has to be longitudinal (Faculty). In medical course, there is too much cognitive competition. [HASS] could be therapeutic if injected at regular intervals (HASS faculty). The university needs to engage the parents and the students, explain why the humanistic aspect is important (Faculty).

And, finally, the voice of the leadership: We are developing holistic, humanistic physicians. HASS is crucial for grooming and developing [these] physicians (Dean, Medical College). Six weeks alone is not the answer; integration throughout [the curriculum] is a good idea. It brings relevance, helps students understand that this is part of their [overall] studies. The [senior-most] leadership keeps pushing for this transition [so] there is no battle to convince people here. There is no question about the commitment to giving medical students a broader education. The question is, how best to do it (Founding Dean, Faculty of Arts and Sciences).

\section{Discussion}

The initial analysis identified the broader themes to which the various respondents contributed (Figure 2). This is representative of and limited to the respondents' own understanding of HASS, expectations and larger needs and concerns.

The next level of analysis examined differences between and within different groups of respondents. Both HASS and basic and clinical science faculty who subsequently teach students in the medical college largely perceived HASS as encouraging creative and critical thinking, fostering confidence and openness, and positively impacting student behaviour as reported by other studies.8,9 Student perception of HASS changed as they progressed through the years and appreciated its impact at different stages. Particularly upon reaching the clinical years of study, students are able to link their role as knowledgeable and clinically-competent medical practitioners to the importance of knowing the world and its people better. Students also believe that interests beyond medicine, encouraged by HASS, develop resilience and are an outlet against burnout. An objective of the HASS course is to develop skills of reflection, argued to be necessary for intrinsic well-being in the face of a consumer medical education model that promotes entitlement and materialism in students. ${ }^{10}$ An unexpected advantage of the HASS course identified is the opportunity that it provides for students to bond and connect with each other. This aligns with the terminal objective of the module to appreciate diversity and the "other". Faculty members also perceived that HASS has brought about a change in students, suggesting that groups formed in HASS on the basis of common sub-cultures probably contribute to students' sense of identity. This can be a source of strength for those in the majority, but could be alienating for those in the minority 11 and contrary to the goal of the HASS module to inculcate pluralism and respect for all. Whether these sub-cultures sustain, evolve, devolve or dissolve requires further study, but ability to work well in teams is important for healthcare professionals. ${ }^{12}$ Several study participants recommended that HASS be taught longitudinally throughout the curriculum, and proposed strategies for this. The institution has plans to introduce a Faculty of Arts and Sciences and a programme whereby all medical students are exposed to a broader education prior to the start of the medical curriculum. Till such a programme is formally in place, students and faculty members agreed that HASS should be a longitudinal theme with elective or selective opportunities throughout the five-year curriculum and exposure to guest speakers. However, students felt that there would be resistance from

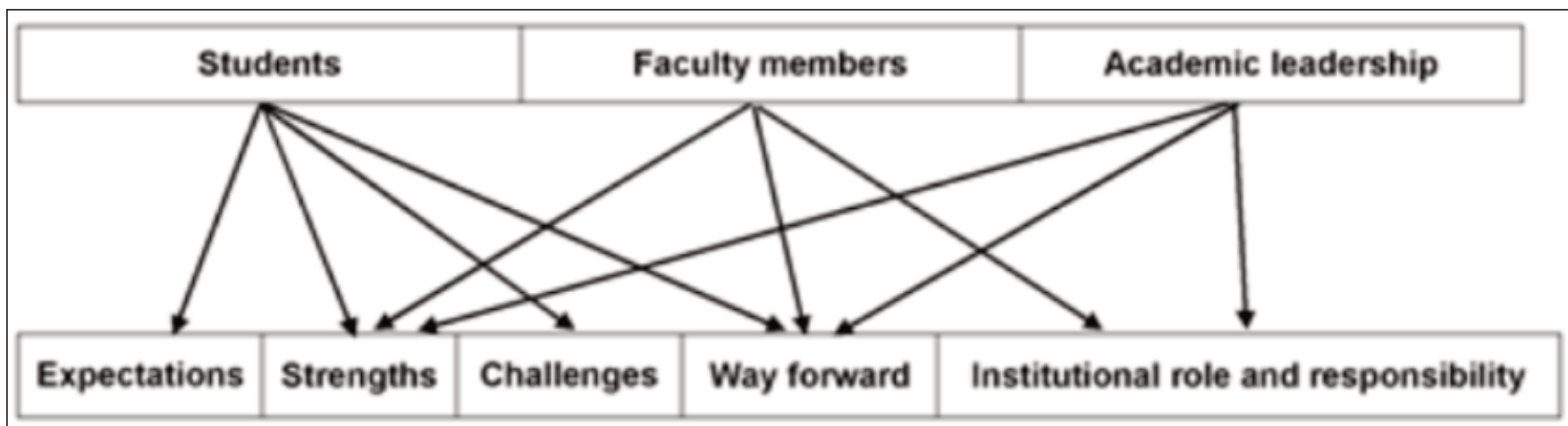

Figure-2: Distribution of data themes across respondents. 


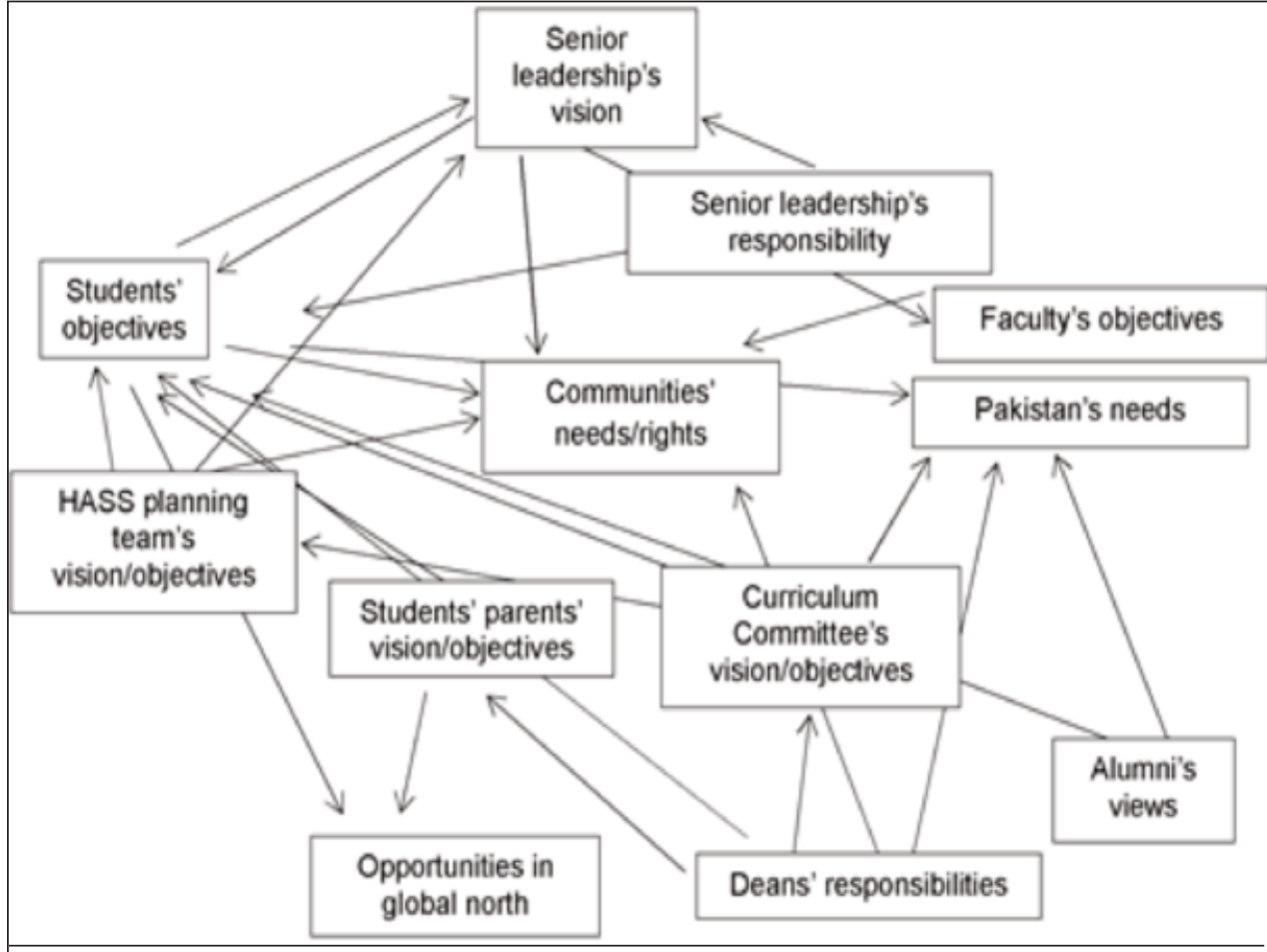

Figure-3: 'Messy' map of undergraduate medical education stakeholder issue and priorities. in the students' education and the institution as a whole. The narratives were therefore analysed using Burns' systematic analysis approach. ${ }^{13}$ Burns argues that sustainable change is possible only after the important inter-relationships and connectedness of an issue are identified. The process of analysis starts with the creation of a 'messy map' that shows the relationship between various issues within the larger theme that is being explored. This approach was used to map the relationship between various stakeholders (Figure 3 ) on the premise that behind issues are stakeholders. These stakeholders of undergraduate medical education have their rationale and objectives which are important to understand if a position is to be taken on the integration of HASS in UGME.

the medical college faculty members, identifying lack of appreciation for non-medical subjects as a challenge to making HASS a longitudinal course. This perception was not reflected by the faculty members themselves who recommended integrating HASS throughout the curriculum. The responsibility of the institution towards supporting and maintaining HASS also has concurrence from the university leadership. A shift to greater emphasis on HASS, either as a longitudinal theme or as a mandatory liberal arts programme prior to start of the medical curriculum, will require strategic change management and stakeholder buyin. The faculty held the view that the institution has a role to play by acknowledging HASS as a trademark of its medical education programme - within and without the university.

The final level of analysis focussed on synthesising the inter-connectedness or divergence of thoughts of the four speakers in this study within the larger issue of impact and future of HASS. What the participants say is important is to understand the impact of HASS not only on students, but also those who have a stake

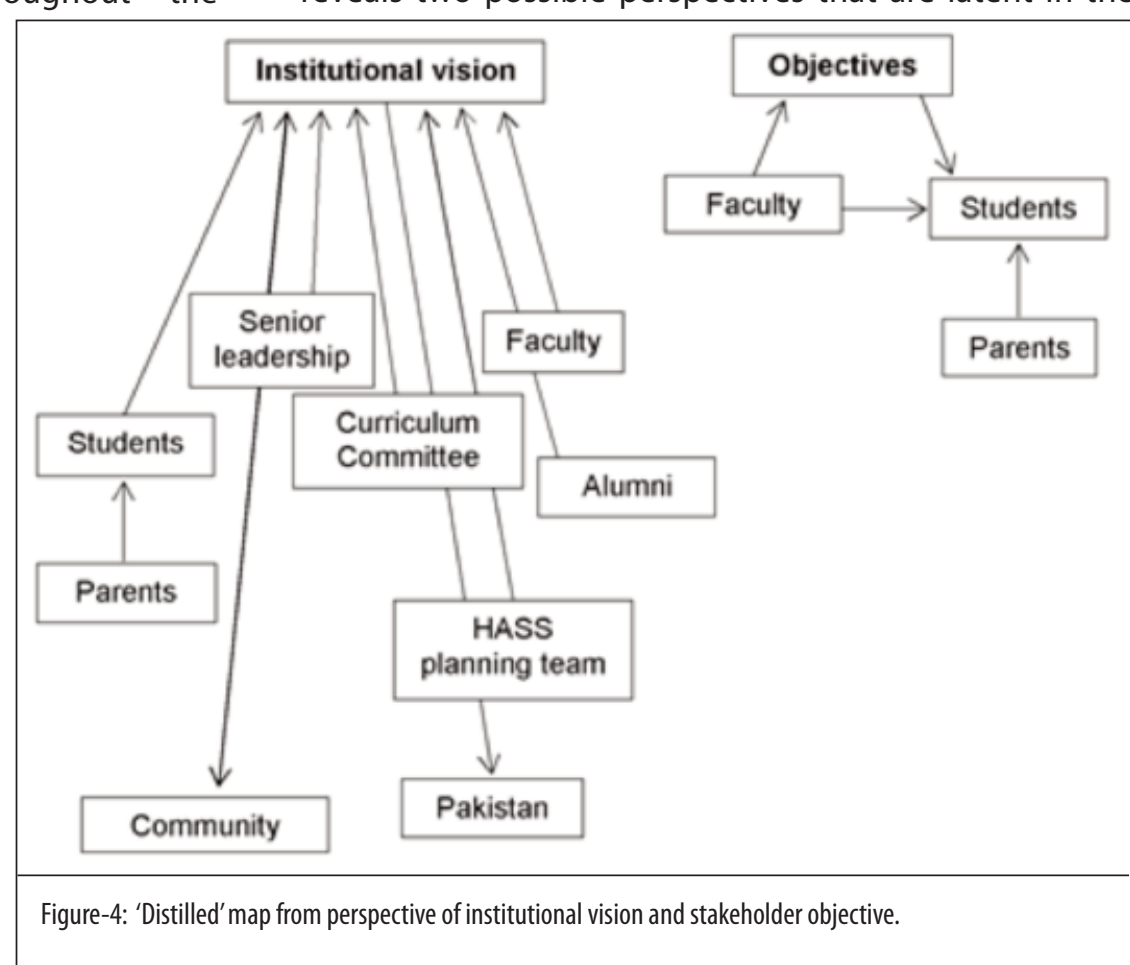

This chaotic, but holistic, web was organised to draw attention to a set of relationships that can help determine the position of HASS in UGME. The distilled map (Figure 4) reveals two possible perspectives that are latent in the 
inter-relationship of the vision and objectives of various stakeholders. There appears to be a distinction between those who define or implement the long-term institutional vision and those who are more focussed on objectives which may be short-term or limited in nature. The objectives-driven group are comfortable in the acquisition of a limited skill-set for specific tasks, for example, being a doctor which requires knowledge of the scientific basis of disease. Those focussing on the institutional vision are also interested in development of scientific knowledge and skills, but within a social and humanistic framework that eventually benefits a wider community. This approach is also aligned with social accountability as an important outcome of medical education. ${ }^{14}$

The HASS curriculum is driven by the assumption that an integrated knowledge base is needed for a medical student to become a "good" doctor. This is in line with the vision of the institution's senior leadership and the course set by the Curriculum Committee. The senior leadership, with its commitment to the institutional vision, shoulder the responsibility of creating the infrastructure and providing resources for the faculty to develop a good future doctor. Interestingly, this is also revealed in the narratives of students and faculty, which in addition to the overall vision and an objective-based approach to medical education speak towards the importance of integrated knowledge. This strengthens the case of HASS and positions it as an important thread to be sustained by the institution regardless of market-driven features. As stakeholders, students and their parents may not appreciate the immediate impact on a broad-based education. However, the institution has the responsibility to be normative and plot a course that may be contrary to the immediate gains of medical education as perceived by these stakeholders.

This study has revealed that exposure to HASS is largely perceived by students and faculty alike as integral to the development of a holistic medical practitioner who appreciates the socio-cultural context. The existing HASS curriculum can be further strengthened by integrating the contents throughout the five-year programme and continuing HASS as a longitudinal theme till such time as a broader pre-medical liberal arts education model is established.

The participant sampling strategy may be perceived as a limitation of the current study. While there may have been a self-selection bias introduced in the case of students and faculty who chose to participate, informal feedback from non-participating students anecdotally generally supports the perceptions and views given here. The study was also limited in its scope, as others in the field, ${ }^{9}$ in that it did not directly measure long-term impact of teaching of humanities on physicians' practice. However, the results of this evaluation study are relevant to all medical schools that aspire to develop "good" physicians and not mere technocrats, especially in the context of developing countries.

\section{Conclusion}

The model for teaching/learning HASS can be adopted by other institutions that have pre-entry limitations and/or regulatory body requirements that preclude a more extensive HASS curriculum or background. The learning gained from this study is also relevant to medical education policy-making bodies as our experience with the HASS module supports the need for integration of HASS in medical schools. However, more advocacy is recommended to achieve buy-in of all stakeholders. Furthermore, challenges pertaining to additional time and resources required in the medical curriculum for humanities and related financial costs and feasibility need to be addressed.

Disclaimer: Part of this work was shared as an oral presentation at the Chinese University Medical Education Conference (CUMEC) in Hong Kong in March 2018.

\section{Conflict of interest: None. \\ Source of Funding: None.}

\section{References}

1. Macnaughton J. The humanities in medical education: context, outcomes and structures. Med Humanit. 2000; 26:23-30.

2. Boudreau JD, Fuks A. The humanities in medical education: ways of knowing, doing and being. J Med Humanit. 2015; 36: 321-36.

3. Calman KC. The arts and humanities in health and medicine. Public Health. 2005; 119:958-9.

4. Physicians for the twenty-first century. Report of the project panel on the general professional education of the physician and college preparation for medicine. J Med Educ. 1984; 59:1-208.

5. Holmboe E. Bench to bedside: medical humanities education and assessment as a translational challenge. Med Educ. 2016; 50: 275-8.

6. Brett-MacLean P. Use of the arts in medical and health professional education: University of Alberta Health Sciences Journal; 2007. [Online] [Cited 2018 June 8]. Available from: URL: http://www.academia.edu/10289891/MUSA_Use_of_the_Arts_in_Medical_and_Healt h_Professional_Education.

7. Ghias K, Khan KS, Ali R, Azfar S, Ahmed R. Stretching the boundaries of medical education: A case of medical college embracing humanities and social sciences in medical education. Pak J Med Sci. 2016; 32: 911-6.

8. Mangione S, Chakraborti C, Staltari G, Harrison R, Tunkel AR, Liou KT, et al. Medical students' exposure to the humanities correlates with positive personal qualities and reduced burnout: a multi-institutional U.S. survey. J of Gen Int Med. 2018; 33: 628-34.

9. Ousager J, Johannessen $\mathrm{H}$. Humanities in undergraduate medical education: a literature review. Acad Med. 2010; 85: 988-98.

10. Eley DS, Stallman H. Where does medical education stand in nurturing the 3Rs in medical students: Responsibility, resilience and resolve? Med Teach 2014; 36: 835-7. 
11. Hutchison CB. What happens when students are in the minority: ex periences and behaviors that impact human performance. Lanham, USA: Rowman \& Littlefield, 2009

12. Bridges DR, Davidson RA, Odegard PS, Maki IV, Tomkowiak J. Interprofessional collaboration: three best practice models of interpro fessional education. Med Educ Online. 2011;16: 22-4.

13. Burns D. Participatory systemic inquiry. IDS Bulletin. 2012; 43: 88-100.

14. Dharamsi S, Ho A, Spadafora SM, Woollard R. The physician as health advocate: translating the quest for social responsibility into medical education and practice. Acad Med. 2011; 86:1108-13. 